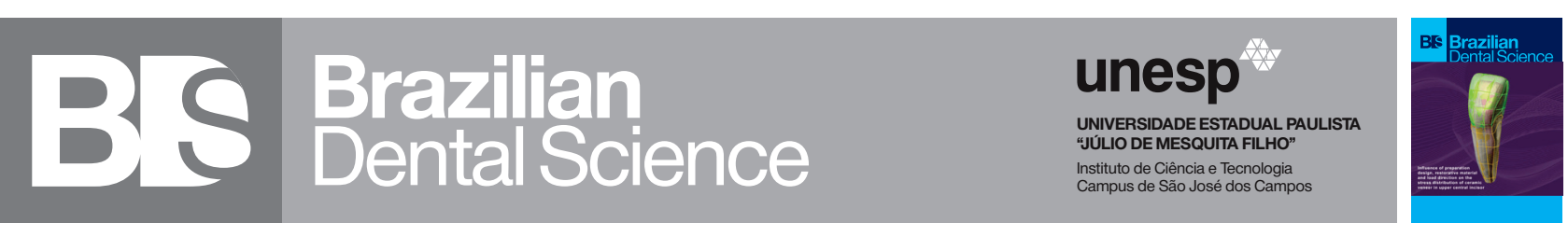

\title{
Cone Beam Computed Tomography Based Sex Estimation by Volume of Odontoid Process of The Second Cervical Vertebra
}

Estimativa sexual baseada em tomografia computadorizada de feixe cônico pelo volume do processo odontóide da segunda vértebra cervical

Andre Luiz Ferreira COSTA ${ }^{1}$, Ana Amelia BARBIERI ${ }^{2}$, Bianca Costa GONÇALVES ${ }^{1}$, Camila Felisbino SILVA ${ }^{2}$, Celso Massahiro OGAWA ${ }^{1}$, Cristiane de Almeida Baldini CARDOSO ${ }^{1}$, Karolina Aparecida Castilho FARDIM ${ }^{1}$, Sérgio Lucio Pereira de Castro LOPES ${ }^{1}$

1 - Postgraduate Program in Dentistry, Cruzeiro do Sul University (UNICSUL), São Paulo, SP, Brazil.

2 - Department of Diagnosis and Surgery, Institute of Science and Technology, São Paulo State University (UNESP), São José dos Campos, SP, Brazil.

\section{ABSTRACT}

Objective: The aim of this study was to evaluate whether the volume of odontoid process of the second cervical vertebra on CBCT images can be used for sex estimation. Material and Methods: The volume of odontoid process on CBCT images of 138 subjects was measured. In addition, the patients were classified into five age groups. The comparisons between the groups in relation to sex and age were performed by using Mann-Whitney's test and Kruskal-Wallis' test, respectively. The ROC curve was used to assess the sensitivity and specificity of the volume to determine the sex. Results: No statistically significant difference was observed between age and volume. Males had significantly larger volumes than females. Values of volume equal to or greater than 1.254 $\mathrm{mm}^{3}$ have sensitivity of $68.2 \%$ and specificity of $68.1 \%$ to determine male sex. Conclusion: The volume of the odontoid process tends to be larger in males than in females and can be used as sex estimation.

\section{KEYWORDS}

Cone beam computed tomography; Diagnostic imaging; Sex determination processes; Image processing; Computer-assisted.

\section{RESUMO}

Introdução: $O$ objetivo deste estudo foi avaliar se o volume do processo odontóide da segunda vértebra cervical em imagens de TCFC pode ser usado para estimativa do sexo. Material e Métodos: $\mathrm{O}$ volume do processo odontóide em imagens CBCT de 138 indivíduos foi medido. Além disso, os pacientes foram classificados em cinco faixas etárias. As comparações entre os grupos em relação ao sexo e idade foram realizadas por meio dos testes de Mann-Whitney e Kruskal-Wallis, respectivamente. A curva ROC foi utilizada para avaliar a sensibilidade e especificidade do volume para determinar o sexo. Resultados: Não foi observada diferença estatisticamente significativa entre idade e volume. Os machos tiveram volumes significativamente maiores do que as fêmeas. Valores de volume igual ou superior a 1,254 mm3 apresentam sensibilidade de 68,2\% e especificidade de $68,1 \%$ para determinação do sexo masculino. Conclusão: O volume do processo odontóide tende a ser maior no sexo masculino do que no feminino e pode ser usado como estimativa do sexo.

\section{PALAVRAS-CHAVE}

Tomografia computadorizada de feixe cônico; Diagnóstico por imagem; Processos de determinação do sexo; Processamento de imagem; Assistido por computador. 


\section{INTRODUCTION}

$\mathrm{T}$ he forensic anthropological method for - estimation of age and estimation of sex by measuring bone structures is widely used given its mathematical precision [1]. In Forensic science, the bone remains, are important instrument due to their resistance to destruction. In many cases, small pieces are the only organs available to estimate the sex of unknown individuals [2]. This fact shows the importance of studies aimed at assessing specific parameters in these elements of subjects, thus conferring greater reliability to the already-established parameters related to a population [3].

Sex and age estimation are auxiliary methods that can be used by professionals who study human identification processes. However, there is a relative scarcity of specific morphometric patterns for sex and age estimation in the contemporary population regarding bone findings of unknown persons [4].

Cone beam computed tomography (CBCT) is an imaging system for the head and neck region, being of great diagnostic value in the clinical dental and otolaryngology practice $[5,6]$. In addition, it is an auxiliary examination with significant advantages as it produces high spatial resolution images of bone tissues with no overlapping areas, including possibility of multiplanar reconstructions and accurate measurement of images and distances between anatomical structures in the maxillofacial complex [5]. These features emphasize the importance of carrying out a great number of studies using CBCT as a support tool for forensic investigation [7].

The odontoid process, or dens, is an extension of the body of the second cervical vertebra (C2), articulating with the anterior arch of the atlas $[8,9]$. To the best of our knowledge, there is no previous study investigating sex and age differences on the basis of the volume of odontoid process.

Therefore, the present study was undertaken to investigate the usefulness of a method designed to assess the volume of odontoid process by using CBCT for sex estimation.

\section{MATERIAL AND METHODS}

This is a retrospective study and was conducted in accordance with the ethical standards established in the 1964 Declaration of Helsinki and approved by the Institutional Review Board of the São Paulo State University (UNESP).

This study's sample included 138 subjects (66 males and 72 females, aged between 18 and 74 years) who underwent CBCT scan for planning of orthodontic or dental implant treatment at the Division of Dentomaxillofacial Radiology, School of Dentistry of São José dos Campos, UNESP. CBCT images were acquired by using an i-CAT scanner (Imaging Sciences, Hatfield, PA, USA) with the following parameters: $120 \mathrm{kVp}, 37.07$ $\mathrm{mA}$, voxel size of $0.25 \mathrm{~mm}$, field of view of 13.0 $\mathrm{x} 16.0 \mathrm{~cm}$ and acquisition time of $26.9 \mathrm{~s}$. The images were chosen by one dentomaxillofacial radiologist. Images of patients who had any type of pathological condition or mandibular fracture were excluded. Poor images or those containing artifacts compromising the visualization of the area of odontoid process were eliminated as well.

Both males and females were divided into five age groups adapted from Gamba et al. [7]: 18 to 30 years, 31 to 40 years, 41 to 50 years, 51 to 60 years and over 60 years.

\section{Image Analysis}

The DICOM (Digital Imaging and Communications in Medicine) images were imported into an open-source segmentation software (ITK-SNAP, version 3.0, Cognitica, Philadelphia, PA, USA) and analysed on a 23.8inch LCD monitor (Dell Ultrasharp, wide-screen flat-panel monitor).

The volumetric analysis of the odontoid process was performed in the manual mode. The borders of the odontoid process were delimitated by a dentomaxillofacial radiologist by means of multiplanar reconstructions to define the region of interest (ROI) for segmentation (Figure 1). Whenever needed, the process was repeated for each CBCT slice until the entire bone was segmented. The volume of each bone was automatically calculated in $\mathrm{mm} 3$ by using the software. 

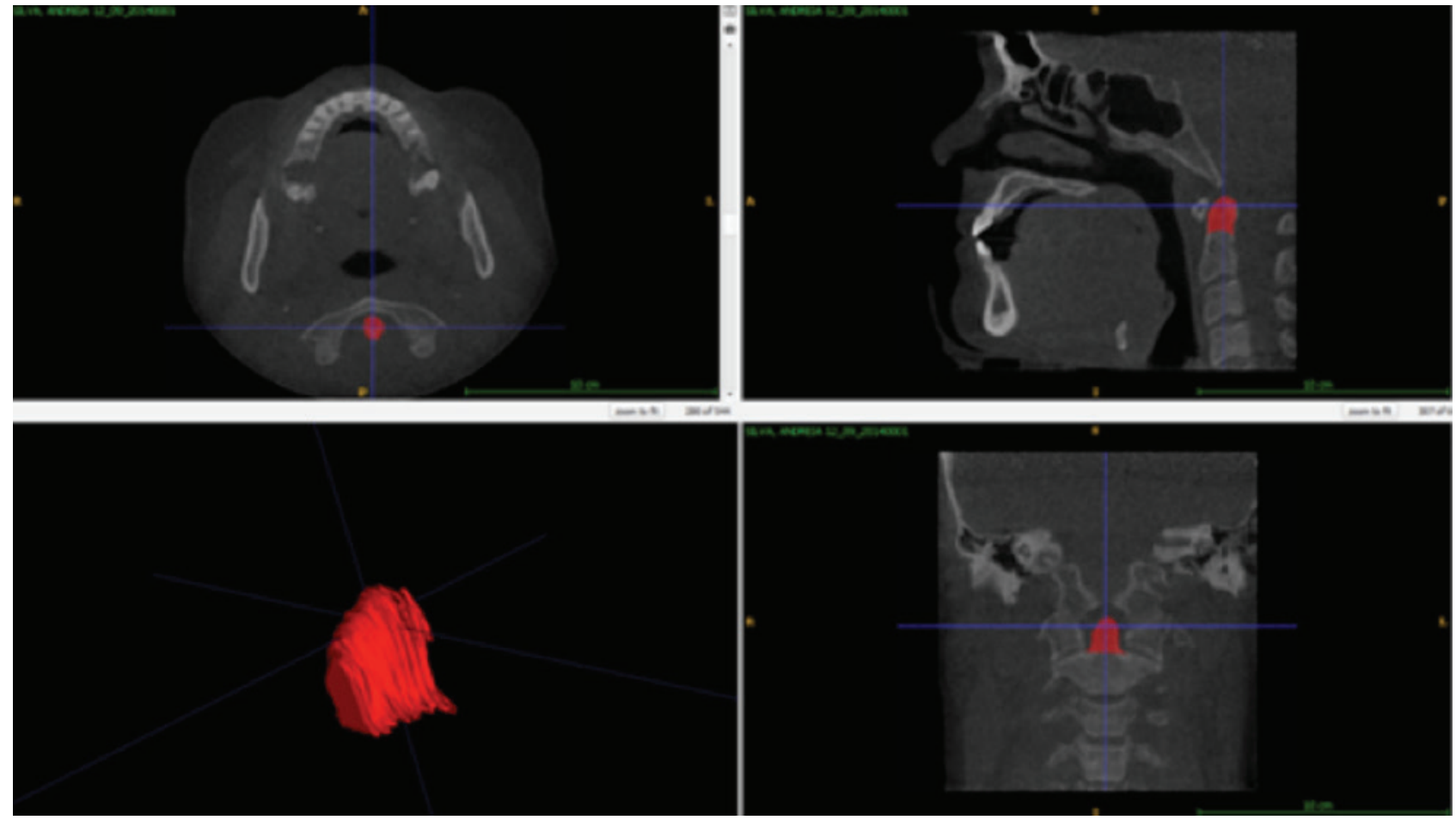

Figure 1 - View of three-dimensional segmentation of odontoid process in ITK/SNAP software showing multiple planar views (axial, sagittal and coronal) with segmentation and 3D surface model displaying volume rendering.

After a 15-day interval, all the measurements were repeated for intra-rater reliability analysis.

\section{Statistical Analysis}

Exploratory data analysis was performed by means of summary measures (i.e. frequency, percentage, means, standard deviation, minimum, median and maximum) and agreement between the two moments of volume measurement was assessed by using intraclass correlation coefficient. The comparison between the groups in relation to sex estimation was performed by using Mann-Whitney's test, whereas Kruskal-Wallis' test was used to compare the volume between age groups. The logistic regression model was used to estimate the chance of an individual being male based on the increase in the volume of odontoid process.
The receiver operating characteristics (ROC) curve was used to assess both sensitivity and specificity of the volume of odontoid process to determine male sex.

Non-parametric methods were used in the analyses because the volume of odontoid process had no normal distribution. A significance level of $5 \%$ was adopted in all analyses.

\section{RESULTS}

Volume measurements were performed at two different times, with Figure 2 showing the descriptive measures of both moments. Figure 2 shows that the method has excellent repeatability as the intra-class correlation coefficient is 1.00 and the scatter plot closely resembles a straight line. 


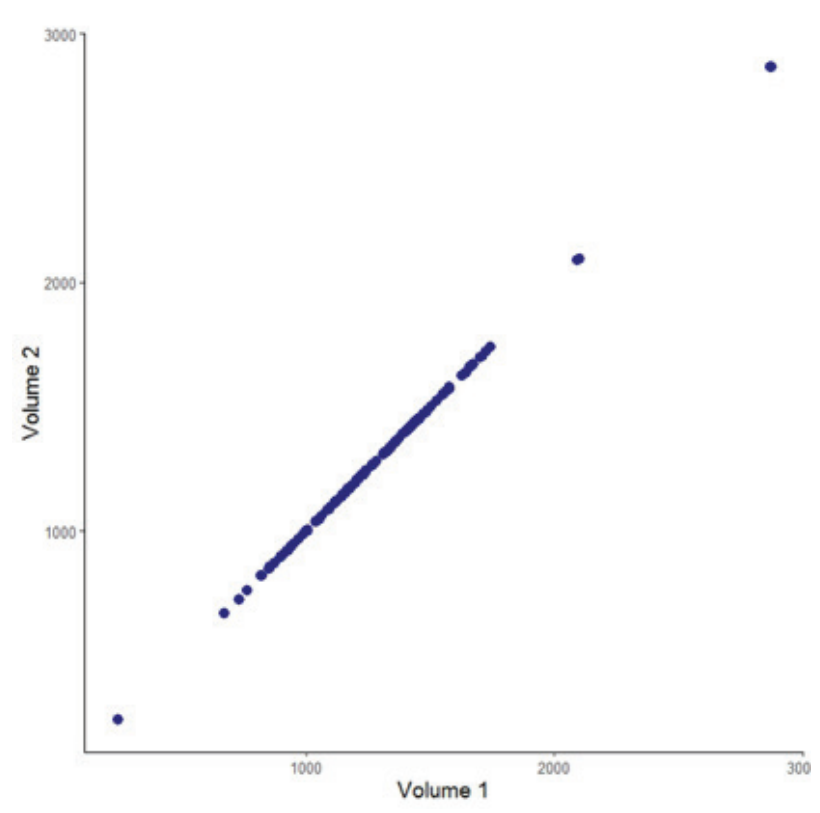

Figure 2 - Scatter plot of the two volume measurements.

Tables 1 and 2 show the comparison of volume between sexs as well as between age groups, respectively. Mann-Whitney's test ( $\mathrm{p}<$ 0.001 ) showed that males had a greater volume (median $=1,382)$ than females (median $=$ 1,165). There was no statistically significant difference between age and volume $(\mathrm{p}=0.366$; Kruskal-Wallis' test).

Adjusting a Logistic Regression model to the data, in order to predict sex from the volume, a Chances Ratio (OR) of 1.352 with 95\% CI $=(1.161 ; 1.575)$ was obtained. This OR was calculated considering a variation in $100 \mathrm{~mm} 3$ in the volume, that is, the increase in $100 \mathrm{~mm} 3$ in volume increases the chance of the patient if male in $35.2 \%$ (p-value < 0.001)

Figure 3 shows that volume values higher than or equal to 1.254 have $68.2 \%$ sensitivity and $68.1 \%$ specificity to determine male sex. The area under the curve (AUC) is 0.708 (95\%CI; $0.621-0.795)$.

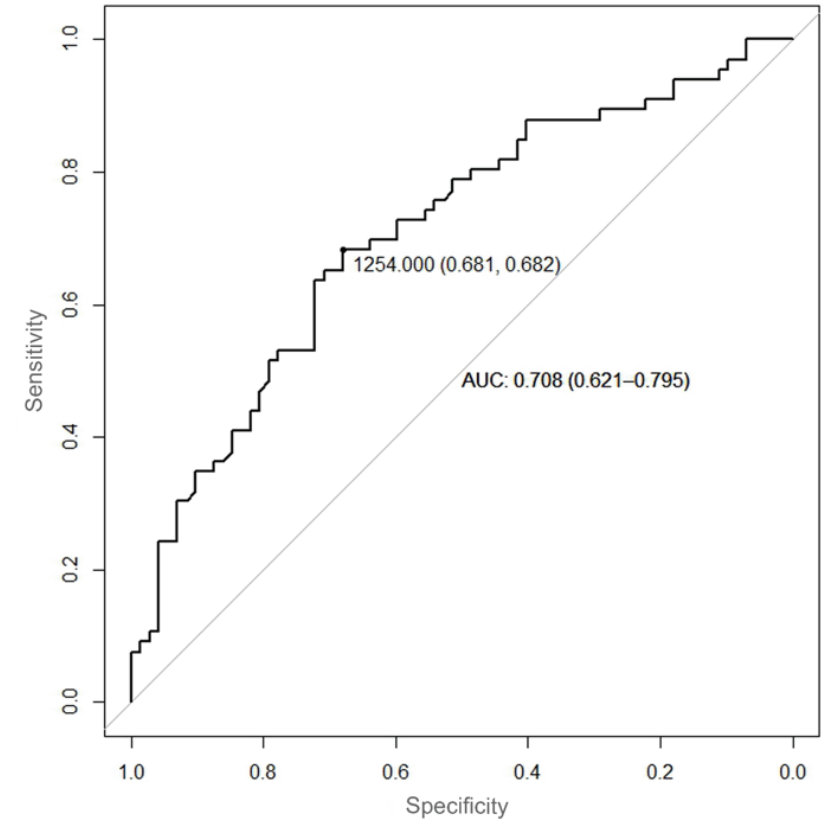

Figure 3 - ROC curve to predict male sex from volume.

\section{DISCUSSION}

In forensic anthropology, one of the fundamental steps to obtain the anthropological profile relies on the estimation of the individual's sex [10]. For anthropological examination of human bones, in which sexual and somatic traits of the body are no longer present, the estimation is based on studies of osseous components such as pelvis, skull and long bones. The uniqueness of anatomical structures and their non-pathological variations are reliable bases for individual identification in many forensic contexts. However, occasionally, conventional techniques of sex estimation may not be usable due to the postmortem deterioration of the human body [11]. New methods for estimating identity when human remains or portions are compromised due to different motives (natural disasters, explosions, and mutilations) are always welcome to help.

Sex dimorphism can be demonstrated by studying important parts of the human skeleton, which is of great value in forensic medicine and especially in the postmortem identification of individuals [12]. In the absence of pelvis, skull is the most suitable structure for sex estimation 
because it presents relevant sexual dimorphism [13].

Previous studies have used structural analysis, mainly of the skull and mandibles, in an attempt to determine a pattern of their behavior in relation to age and sex so that they could be used in forensic dentistry as a determinant for identification of individuals. In these analyses, many of them made use of CBCT imaging as it is an easily accessible examination. CBCT analysis relies on software using linear, angular and volumetric measurement tools, with the great advantage of preserving the anatomical piece and being a type of non-destructive intervention.

Among the various structures of the maxillo-mandibular complex addressed for the purpose of sex estimation, we found studies that evaluated the horizontal position of the mental foramen [14] and its dimensions [15] on CBCT images. In these studies, the authors concluded that mental dimensions tend to be larger in females with advancing age (after 50 years) in relation to males due to hormonal changes, but that their horizontal position was not a factor determinant for determining sex. Our study evaluated a cervical vertebrae structure (i.e. dens) which, unlike the mental foramen, can be influenced by hormonal changes and undergo dimensional changes related to the presence or absence of teeth and periodontal diseases. This, in turn, could affect the reliability of the results regarding their use as sex predictor as they are interpreted as a structure less susceptible to external influences. This observation underlies the choice of a forensic tool with greater stability in relation to changes not related to the aging process only.

As well as the mental foramen, other studies have evaluated different structures by using CBCT for predicting sex. Position of the mandibular lingual [16], volume of the mandibular condyle [17] and angulations of the mandibular fossa and articular tubercle [18] are structures which were shown to be useful to estimate the sex of individuals. However, it is known that bone structures of the temporomandibular joints (TMJ) are often subject to being affected by degenerative processes (e.g. osteoarthritis) [19] and systemic changes (e.g. gout or rheumatic processes) [20], which could influence the actual assessment for forensic purposes of sex identification. As well as the mandibular lingula, which is a structure subject to remodeling process regardless of age, the insertion of the sphenomandibular ligament can also depend on the greater or less demand. In this sense, dens was analysed here because it seems to play a promising role as a more reliable alternative for sex estimation. Taking into account its functional physiological aspect, dens does not undergo pronounced degenerative changes, which could result in errors in the calculation of its volume. Alar ligament, anterior and posterior atlantoaxial ligaments, and transverse ligament of the atlas form a complex that works synchronously to cushion the articular structure of the dens, in addition to stabilizing it during movements and favoring its preservation [21].

In this study, volumetric analysis of the second cervical vertebra (dens) by means of CBCT proved to have a predictive capacity in differentiating between male and female sexs (Table I), with a 95\% probability of assertiveness, which can be considered a high value for this methodology in the estimation of the sex of individuals. Comparatively to those studies using other structures such as mental foramen, mandibular lingula and bone structures of the TMJs, this rate varied between 70 to $90 \%$. This indicates what we had previously highlighted about these methodologies for forensic purposes.

Table III shows the sensitivity and specificity rates for this method in determining male sex identity, respectively $68.2 \%$ and $68.1 \%$, when the volumetric values were greater than $1.254 \mathrm{~mm}^{3}$. These rates can be considered quite significant compared to studies in which volumetry of cranial structures was used to determine sex. One can cite a study by ManhaesCaldas et al. [22], who assessed the volumetry of dental crowns for estimation of sex, and those by Urooge \& Patil [23] and Choi et al. [24], who calculated the volume of the maxillary and 
frontal sinuses, respectively, for this purpose. We emphasize that structures such as paranasal sinuses and dental crowns may not be stable enough as the dens, a finding reported here. Sinuses can often be affected by pathological processes that alter bone dimensions or even the internal content, such as sinusopathies. Similarly, dental crowns are susceptible to wear and tear, fractures and caries disease, which can prevent its use for the purpose of differentiating the sexs.

Still on the sensitivity and specificity of the sex estimation methods, Papaioannou et al. [25] established criteria to determine sex based on the scapula and clavicle in modern Greeks. A total of 147 scapulas and 147 clavicles were analysed, being 66 females and 81 females. Eight and six measurements were performed on the scapula and clavicle, respectively. The results showed pronounced sexual dimorphism, which was attributed mainly to differences in size between the two groups. The method of statistical classification showed evidence of hit rates higher than 95\%. These results corroborate those found in the present study, with a statistically significant difference in the volume of odontoid process for both sexs. The MannWhitney's test $(\mathrm{p}<0.001)$ showed that males had a greater volume (median $=1.382$ ) than females (median $=1,165$ ), as seen in Tables I and II. Values greater than or equal to 1.254 have $68.2 \%$ sensitivity and $68.1 \%$ specificity to determine male sex (Figure 3).

In the context of the age estimation based on bone development, one initially tries to assess in which phase of the individual's life he or she deceased, since each phase of the life has peculiar characteristics in his or her development that should be explored. The investigation of chronological age can be based on one or more characteristics. Estimation of age based on odontometric results contributes to the legal judgment on the chronological age of individuals whose age is uncertain. In the present study no statistically significant differences were observed between age groups regarding the volume of odontoid process, as can be seen in Table II.

In view of the above, the odontoid process was shown to be a sex indication and more studies in this area are suggested. Therefore, we recommend that volumetric analysis of the cervical vertebrae should be performed by means of tomographic images to corroborate the existence of sexual dimorphism based on these anatomical structures.

\section{CONCLUSION}

According to the methodology used in the present study, it was observed that the mean volume of $\mathrm{mm} 3$ for the odontoid process was higher in men than in women, suggesting that the volume of this structure can be used for sex estimation.

\section{Acknowledgments}

This research was supported by a grant from FAPESP, process 2019/00495-6

\section{Conflict of Interest}

None of the authors has any potential conflict of interest.

\section{Funding}

This study was partially supported by São Paulo Research Foundation (FAPESP) grant number: 2019/00495-6

\section{Regulatory Statement}

This study was conducted in accordance with all the provisions of the local human subject's oversight committee guidelines and policies of: the Institutional Review Board of the São Paulo State University (UNESP). The approval code for this study is: 04619712.0.0000.5419.

\section{REFERENCES}

1. Albanese J. A method for estimating sex using the clavicle, humerus, radius, and ulna. J Forensic Sci. 2013;58(6):1413-9.

2. Prabhu S, Acharya AB. Odontometric sex assessment in Indians. Forensic Sci Int. 2009;192(1-3):129 e1-5. 
3. Kharoshah MA, Almadani 0, Ghaleb SS, Zaki MK, Fattah YA. Sexual dimorphism of the mandible in a modern Egyptian population. J Forensic Leg Med. 2010;17(4):213-5.

4. Gomez-Valdes JA, Quinto-Sanchez M, Menendez Garmendia A, Veleminska J, Sanchez-Mejorada G, Bruzek J. Comparison of methods to determine sex by evaluating the greater sciatic notch: Visual, angular and geometric morphometrics. Forensic Scillnt. 2012;221(1-3):156 e1-7.

5. de Carvalho ABG, Ferreira Costa AL, Fuziy A, de Assis ACS, Castro Veloso JR, Coutinho Manhaes LRJ, etal. Investigation on the relationship of dimensions of the maxillary sinus drainage system with the presence of sinusopathies: a cone beam computed tomography study. Arch Oral Biol. 2018;94:78-83.

6. Guldner C, Zimmermann AP, Diogo I, Werner JA, Teymoortash A. Agedependent differences of the anterior skull base. Int J Pediatr Otorhinolaryngol. 2012;76(6):822-8.

7. Gamba TO, Yamasaki MC, Groppo FC, da Silveira HLD, Boscolo SMA, Sanderink GCH, etal. Validation study of a new method for sexual prediction based on CBCT analysis of maxillary sinus and mandibular canal. Arch Oral Biol. 2017;83:118-23.

8. Gray H,Standring S, Ellis H,BerkovitzBKB. Gray's anatomy : the anatomical basis of clinical practice.39th ed. Edinburgh; New York: Elsevier Churchill Livingstone;2005.

9. Bogduk N. Functional anatomy of the spine. Handb Clin Neurol. 2016;136:67588.

10. Saini V, Srivastava R, Rai RK, Shamal SN, Singh TB, Tripathi SK. Mandibular ramus: an indicator for sex in fragmentary mandible. J Forensic Sci. 2011;56 Suppl 1:S13-6.

11. Michel J, Paganelli A, Varoquaux A, Piercecchi-Marti MD, Adalian P, Leonetti $G$, et al. Determination of sex: interest of frontal sinus 3D reconstructions. J Forensic Sci. 2015;60(2):269-73.

12. Anuthama K, Shankar S, llayaraja V, Kumar GS, Rajmohan M, Vignesh. Determining dental sex dimorphism in South Indians using discriminant function analysis. Forensic Sci Int. 2011;212(1-3):86-9.

13. Hu KS, Koh KS, Han SH, Shin KJ, Kim HJ. Sex determination using nonmetric characteristics of the mandible in Koreans. JForensic Sci. 2006;51(6):1376-82.

14. Rodriguez-Cardenas YA, Casas-Campana M, Arriola-Guillen LE, Aliaga-Del Castillo A, Ruiz-Mora GA, Guerrero ME. Sexual dimorphism of mental foramen position in peruvian subjects: A cone-beam-computed tomography study. Indian JDent Res. 2020;31(1):103-8.
15. Alsoleihat F,Al-OmariFA, Al-Sayyed AR, Al-Asmar AA, Khraisat A. The mental foramen: A cone beam CT study of the horizontal location, size and sexual dimorphism amongst living Jordanians. Homo. 2018;69(6):335-9.

16. Hsu KJ, Tseng YC, Liang SW, Hsiao SY, Chen CM. Dimension and location of the mandibular lingula: comparisons of gender and skeletal patterns using conebeam computed tomography. Biomed Res Int. 2020;2020:2571534.

17. Altan Salli G, Ozturkmen Z Semi-automated three-dimensional volumetric evaluation of mandibular condyles. Oral Radiol.2020.

18. Costa EDD, Peyneau PD, Roque-Torres GD, Freitas DQ, Ramirez-Sotelo $L R$, Ambrosano GMB, et al. The relationship of articular eminence and mandibular fossa morphology to facial profile and gender determined by cone beam computed tomography. Oral Surg Oral Med Oral Pathol Oral Radiol. 2019;128(6):660-6.

19. Dumbuya A, Gomes AF,Marchini L,Zeng E, Comnick CL, Melo SLS. Bone changes in the temporomandibular joints of older adults: A cone-beam computed tomography study. Spec Care Dentist. 2020;40(1):84-9.

20. Konig MF,Faller GT. Acute bilateral pseudogout of the temporomandibular joint. Arthritis Rheumatol. 2020.

21. Jenkins S, Bordes S, Aly I, Jeyamohan S, Ishak B, Iwanaga J, etal. Internal morphology of the odontoid process: anatomic and imaging study with application to c2 fractures. World Neurosurg.2019;127:e1120-e6.

22. Manhaes-Caldas D, Oliveira ML, Groppo FC, Haiter-Neto F. Volumetric assessment of the dental crown for sex estimation by means of cone-beam computed tomography. Forensic Sci Int. 2019;303:109920.

23. Urooge A, Patil BA. Sexual dimorphism of maxillary sinus: a morphometric analysis using cone beam computed tomography. JClin Diagn Res. 2017;11(3):ZC67-ZC70.

24. Choi IGG, Duailibi-Neto EF,Beaini TL, da Silva RLB, Chilvarquer I. The Frontal sinus cavity exhibits sexual dimorphism in $3 \mathrm{~d}$ cone-beam ct images and can be used for sex determination. J Forensic Sci. 2018:63(3):692-8.

25. Papaioannou VA, Kranioti EF, Joveneaux P,Nathena D, Michalodimitrakis M. Sexual dimorphism of the scapula and the clavicle in a contemporary Greek population: applications in forensic identification. Forensic Sci Int. 2012;217(13):231e1-7.

\section{Andre Luiz Ferreira Costa} (Corresponding address)

Postgraduate Program in Dentistry, UNICSUL, São Paulo, SP, Brazil. Date submitted: 2020 Sep 28 